\title{
The Growth of "Green" finance at the global level in the context of sustainable economic development
}

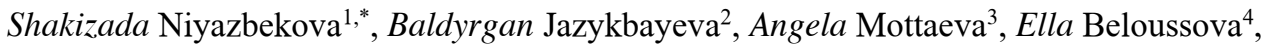 \\ Buldyryk Suleimenova ${ }^{5}$, and Anna Zueva ${ }^{6}$ \\ ${ }^{1}$ Moscow Witte University, Department finance and economy, 119454, 2-I Kozhuhovski p., 12, bd. 1, \\ Moscow, Russia \\ ${ }^{2}$ Karaganda University of Kazpotrebsoyuz, 100009, Karagandy, 9, Akademicheskaya str., Republic of \\ Kazakhstan \\ ${ }^{3}$ Moscow State University of Civil Engineering, 109377, 26, Yaroslavskoye Sh., Moscow, Russia \\ ${ }^{4}$ Saken Seifullin Kazakh Agrotechnical University, 010000, Zhenis av, 62, Nur-Sultan, Kazakhstan \\ ${ }^{5}$ Yessenov University, 139000, 32, microdistrict Aktau, Kazakhstan \\ ${ }^{6}$ Financial University under the Government of the Russian Federation, Leningradskii bld., 86, \\ Moscow, 125993, Russia
}

\begin{abstract}
The paper considers the features of the growth of "green finance". The nuances of the development of the green economy of foreign countries are studied. The analytical data of the green market and issued instruments are presented in the form of figures, data for a number of years. Creating a greener economy requires significant investment, whether it's financing a new electric bus network, building a solar farm, or building power plants powered by renewable energy. In this regard, responsible investing is being developed around the world, which is based on an approach to investing that seeks to include environmental, social and management factors (ESG factors) in the investment decision- making process for better risk management and a sustainable and long-term return on investment.
\end{abstract}

\section{Introduction}

The green bond market - money borrowed to invest in green projects - is a good indicator of the progress countries have made in addressing climate change.

Climate change may still be a point of contention for some policymakers, but investors have become more determined. The money will flow into any type of asset labeled as "green" or " sustainable." All of this forces investors and companies to grapple with what is considered "green" finance, and with funds that are no longer seen as green enough.

Nowadays, many European countries have abandoned the use of plastic bags and are trying to resort to the use of recyclable materials in order to preserve the environment.

\footnotetext{
*Corresponding author: shakizada.niyazbekova@gmail.com
} 
Environmentalists noted that our country is beginning to actively develop in this area, and to confirm these words, we will give an example of the international conference in Skolkovo, which was held in April 2017. At this conference, they separately noted the role of "green" offices in Russia and clarified that they will be the starting point for achieving a "green economy".

\section{Review of the literature}

(Rudenko, 2020), (Wang, Yao \& Zhi, Qiang, 2016).) defines a green economy as based on six main sectors:

- renewable energy;

- green buildings;

- sustainable transport;

- Water resources management;

- Waste management;

- land management [1-5].

We are standing up to the fossil fuel industry to stop all new coal, oil and gas projects and create clean energy for all [6-11].

"Many financial institutions are not quite sure what the universe should be like, but everyone is involved," (BloombergNEF, Dan Shurey, 2012), who tracks green bonds and green loans at Bloomberg NEF.

Scientists (Zadek, 2009) presented three practical principles that national climate funds must adhere to in order to be effective:

National institutions are designed as instruments of economic transformation, not just "Getting" the end point of the global finance pipeline;

Sharing responsibility within purely bureaucratic institutions will not work;

The critical thing is not to "do it right" for the first time, but to create a dynamic system that meets the right standards and is able to develop in the future.

\section{Metods}

Empirical methods were used in the work, which allowed us to study the results. Based on the methods of observation and qualitative comparison, specific facts were collected and phenomena were identified.

\section{Results}

According to a report by the Global Alliance for Sustainable Investment, a group of organizations tracking these movements in five regions from the US to Australia holds at least 30.7 trillion USD in sustainable or green investments, up $34 \%$ from 2016 . Overall, these cash flows account for a third of the tracked assets under management, and in some places have reached more than half.

It should be noted that responsible investment is currently unevenly distributed between countries and continents.

In 2017, HSBC joined a growing number of the world's largest banks in making a financial commitment to sustainable financing and investments to help projects, technologies, and clean energies in delivery of the Paris Agreement and the UN Sustainable Development Goals. HSBC's financial commitment in 2017 came to a total of 100 billion USD by 2025 in the form of facilitation, financing and investments. In the three years included since their commitment, HSBC has so far invested a total of 52.4 billion USD, surpassing the half way 
mark to reaching the goal. The majority of financing and investments by HSBC were in the form of green investments [12-15].

Renewable energy developers have attracted pension funds to support new projects, offering securities with sustainable returns backed by contracts to sell electricity. As the BloombergNEF data showed, this helped create a market for green bonds and loans that barely existed a few years ago.

"These are stable, predictable cash flows," according to Aquila Capital, which oversees the European Renewable Energy Fund, which manages EUR 8.2 billion (USD 9.2 billion). "There are several alternatives that provide a stable income associated with regulated contracts".

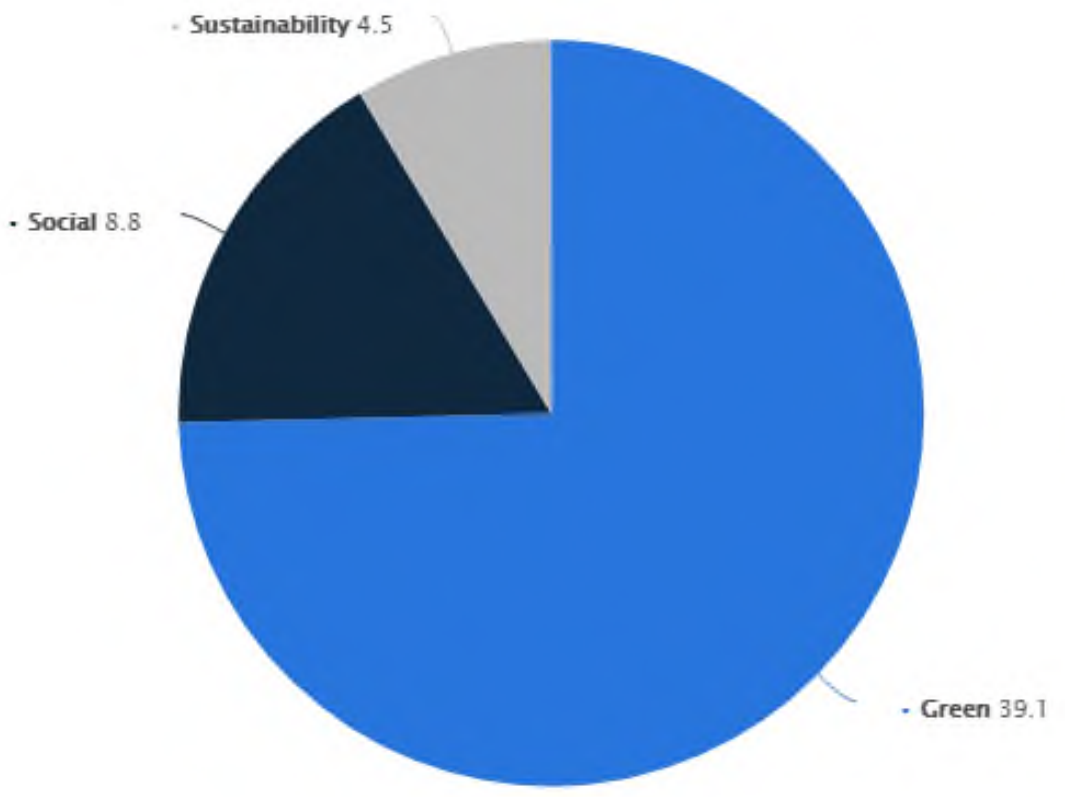

Fig. 1. Cumulative value of sustainable finance investment of HSBC bank between 2017 to 2019, by investment type*(in billion USD). Source: https://www.statista.com/

The Green Economy development model is a powerful tool that:

-establishes the relationship between the policy objectives and the relevant economic, environmental and social aspects;

-predicts the impact of policy measures;

-analyzes the impact of existing policies;

-identifies synergies and cross- sectoral impacts among policy options.

The UN Environment supports countries in developing green economy policy assessments that use green economy models to inform decision- making processes in the context of the Sustainable Development Goals and the Paris Agreement on Climate Change, and works to strengthen the institutional and individual capacity of local and national institutions in Green Economy Action Partnership (PAGE) countries to model green economies $[14,15]$.

Some investments are probably more "green" than others. There is no single definition of what is considered "green" or sustainable finance. Some asset managers want to support 
only clean energy. Others consider the effectiveness or even a strict series of policies on social issues.

There are concerns that broad definitions of sustainability do not make sense, allowing some funds to market themselves as eco- friendly or ethical, even if they are not good for the environment.

Green bond issuance in ASEAN (Fig.2).

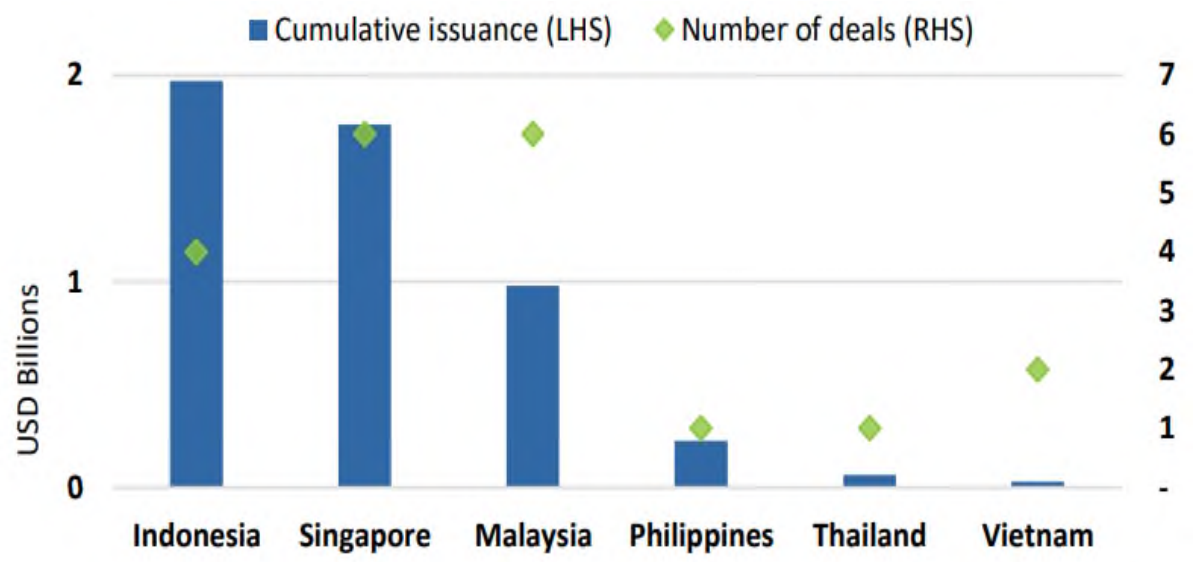

Fig. 2. Green bond issuance in ASEAN. Source:

https://www.climatebonds.net/files/reports/asean_green_fin_istruments_cbi_012019_0.pdf

Green finance is developing rapidly. Financial products such as green labelled bonds, sukuk and loans have become globally recognised as an effective means of directing investment capital towards climate change mitigation as well as climate change resilience and adaptation projects.

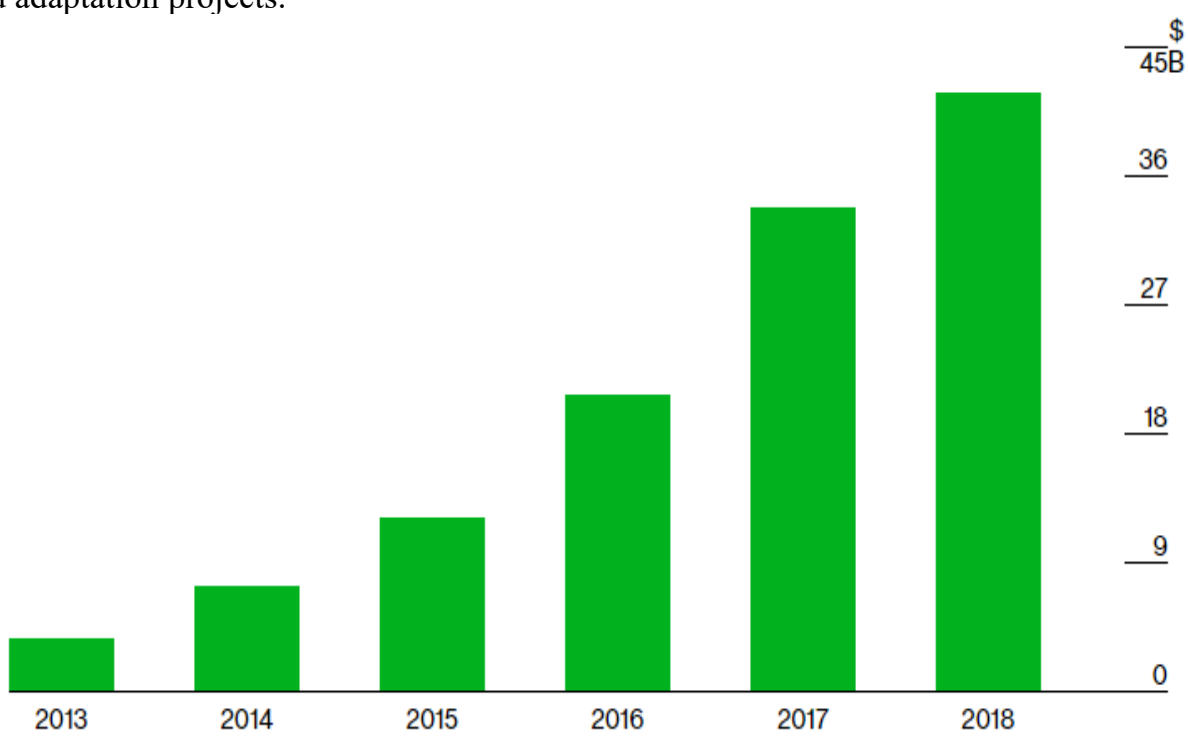

Fig. 3. Indicators of assets under ESG management 2013-2018. Source: Bloomberg Intelligence. 
GSIA has the broadest definition, counting any kind of fund that uses a strategy related to sustainability. The biggest and oldest strategy is negative or exclusion screening, which filters out support for unwanted substances from oil to guns, tobacco and alcohol.

It accounted for USD 19.8 trillion of sustainable assets managed last year, up $31 \%$ from 2016. GSIA also believes that those who buy "best- in- class" assets under certain measures or who follow environmental, social and governance or ESG regulations, Funds that attract corporate advice or encourage shareholder action, also make the cut.

According to the broader strategy 350.org, a campaign that wants to limit funding for oil and coal companies, in addition to broader green investment strategies, is increasingly spending on fossil fuels.

By mid- May 2018, it was estimated that 1,048 institutions managing \$ 8.73 trillion had some sort of strategy limiting fossil fuel financing. And the numbers have doubled in the last four years. The group believes its campaign has outstripped all previous asset sales movements, including those against tobacco and South Africa during the apartheid era.

Changes in the green economy are taking place in the stock markets. According to data compiled by Bloomberg Intelligence, the value of green and ESG funds traded on exchanges in 2017 reached a record 41.6 billion USD [15].

Equity markets are getting greener. Assets under management and ESG funds on the topic sustainable development.

The rise of green finance looks set to continue as most governments around the world focus on how to reduce pollution and greenhouse gases, and more regulators require companies to disclose climate- related risks, leading to more data showing which companies are most vulnerable and a better understanding of how to make money saving the planet.

\section{Discussion}

The experience of the countries has shown the following interesting facts in the field of green finance development.

France. In 2017, France issued its first sovereign green bond, aiming to turn Paris into a financial hub for economic transition. The bond allowed France to borrow EUR 7 billion to support clean energy projects. At the time, it was thought to be the largest issue with the longest maturity date on the green bond market [8-16].

United States of America. The US comes first when it comes to green bonds.

In 2018, such securities were issued for USD 118.6 billion. Total managed assets in the United States using sustainable strategies increased from \$ 8.7 trillion in early 2016 to 12 trillion USD in early 2018, an increase of $38 \%$, according to the Global Sustainable Investment Review. This growth is driven by customer demand: $40 \%$ of US fund managers point to the UN Sustainable Development Goals as a motivation for new investments in sustainable schemes [9], [11-16].

China. At the G20 summit held in Hangzhou in 2016, each head of government agreed on a common goal to promote green finance, a victory for China that was consistent with its own plan to pursue green finance policies. China hopes to encourage more private investment in green sectors to support low- carbon transformation in its economy, driven by policy incentives such as the creation of a green development fund $[12,16]$.

Green finance is developing rapidly in China, as the Chinese Government has developed a Green Credit Policy.

Thus, the green economy is generally aimed at ecology and optimization of production, taking into account the limited space and economy of slowly reproducible resources. In light industry, this is the use of production with a lower emission of pollutants of all kinds 
to the environment and the use of materials that are either completely decomposable or can be recycled without again severe environmental pollution [13, 19-21].

\section{Conclusion}

Thus, according to the provisions of the Global Commission on the Economy and Climate, the transition to a low- carbon sustainable approach can lead to economic growth of 26 trillion USD by 2030 and help create more than 65 million new jobs.

In modern conditions, the importance of financing sustainable development, taking into account climate change, is increasing, which is defined as a promising direction of development by the decision of the United Nations General Assembly at the end of September 2019.

\section{References}

1. K. Al-Sheryani, H. Nobanee, Green Finance: A Mini-Review, SSRN Electronic Journal (2020) 10.2139/ssrn.3538696

2. A.N. Brodunov, V.Ya. Ushakov, Justification of financial decisions in conditions of uncertainty, Bulletin of the Witte Moscow University. Series 1: Economics and management (12), 30-36 (2015)

3. K.G. Bunevich, D.M. Petrov, Development of dual-use technologies based on the cluster approach, Bulletin of the Witte Moscow University. Series 1: Economics and management 1 (3), 75-79 (2013)

4. E.V. Ribokene, Assessment of the current state of small and medium-sized enterprises in the software development industry, Bulletin of Moscow University. S.Yu. Witte. Series 1: Economics and Management 1(24), 71-80 (2018) doi: 10.21777 / 25879472-2018-1-71-80

5. L.G. Rudenko, Assessment of the possibility of sustainable environmental, social and economic development of Russia, Bulletin of Moscow University. S.Yu. Witte. Series 1: Economics and Management 1(20), 20-27 (2017) DOI: 10.21777 / 2307-61352017-1-20-27

6. L.G. Rudenko, N.P. Degtyar, The essence of KPI and its role in enterprise management, Bulletin of Moscow University. S.Yu. Witte. Series 1: Economics and Management 2(21), 50-54 (2017) DOI: 10.21777 / 2307-6135-2017-2-50-54

7. L.G. Rudenko, Priority forms of financial support for small business at the present stage of development of the Russian economy, Bulletin of Moscow University. S.Yu. Witte. Series 1: Economics and Management 3(9), 17-23 (2014) URL: http://www.muiv.ru/vestnik/pdf/eu/eu_2014_3_17-23.pdf

8. B.V. Salikhov, A.V. Semenov, Essence of sustainable development: definition of key concepts and quality integrity, Bulletin of Moscow University. S.Yu. Witte. Series 1: Economics and Management 3(30), 7-14 (2019) doi:10.21777/2587-554X-2019- 3$7-14$

9. O. Semenyuk, T. Abdrashitova, E. Beloussova, N. Nechay, V. Listkov, V. Kurbatova, S. Niyazbekova, The influence of ecology and economic factors on eco-architecture and the design of energy efficient buildings, World Transactions on Engineering and Technology Education 16, 2, 186- 192 (2018)

10. A. Stephan, Green Finance - Call for Papers (2019) 10.13140/RG.2.2.11501.44000 
11. S. Zadek, et al, Radical Simplicity in Designing National Climate Institutions: Lessons from the Amazon Fund (2009) Accountability http://www.zadek.net/wpcontent/uploads/2010/01/Radical-Simplicity-in-Designing-National-ClimateInstitutions_Lessons-from-the-Amazon-Fund.pdf

12. S.Mohd, V. Kaushal, Green Finance: A Step towards Sustainable Development, MUDRA : Journal of Finance and Accounting 5 (2018) 10.17492/mudra.v5i01.13036

13. E. Ojo- Fafore, C. Aigbavboa, W. Thwala, P. Ramaru, Green Finance for Sustainable Global Growth (2019) 10.4018/978-1-5225-7808-6.ch010

14. M.Rashid, M. Uddin, Green financing for sustainability: analysing the trends with challenges and prospects in the context of Bangladesh, International Journal of Green Economics 12, 192 (2019) 10.1504/IJGE.2018.10019192

15. Y. Wang, Q. Zhi, The Role of Green Finance in Environmental Protection: Two Aspects of Market Mechanism and Policies, Energy Procedia 104, 311-316 (2016) 10.1016/j.egypro.2016.12.053

16. R. Owen (Baldock), F. Lyon, G. Brennan, Filling the green finance gap: Government interventions supporting early-stage low carbon ventures, Academy of Management Proceedings, 16419 (2018) 10.5465/AMBPP.2018.16419abstract

17. P. Tereliansky, The variability of fuzzy aggregation methods for partial indicators of quality and the optimal method choice, ARPN J. Eng. Appl. Sci. 11, 9122-9129 (2016) EID:2-s2.0-84983371688. Accessed 21 Jan 2020

18. R.R. Aetdinova, O.N. Balabanova, I.P. Balabanov, The modern methods of increase of management efficiency of small and medium businesses, Life Sci. J. 11(98), 558561 (2014)

19. E. Safargaliev, R. Aetdinova, A. Karimova, Indicators of financial security of small and medium enterprises, Rev. San Gregorio 34, 81-88 (2019)

20. D.D. Burkaltseva, O.G. Blazhevich, O.A. Gabrielyan, et al, Development of the financial security of the state: neutralization of threats, Rev. Incl. 6, 294-312 (2019)

21. D.D. Burkaltseva, L.M. Borsch, S.V. Gerasimova, S.A. Zotova, O.A. Guk, Regional aspect: laying institutional groundworks, In: European Proceedings of Social and Behavioural Science 50, 33, 263-271 (2018) 